\title{
Alert to readers
}

Dear colleagues, readers and all involved in the publication of the Revista Brasileira de Anestesiologia.

With extreme regret and feeling of frustration, I write this editorial to warn our readers of fraud committed by Brazilian authors of a respected University Center, tearing ethical principles and clouding the confidence in the Brazilian study.

The reputation of a journal is retained by the trust of readers. This fact is crucial for clinical research, laboratory and advancement of knowledge. Thus, this type of publication, as well as reviews of the editorial staff, needs to follow rigid ethical principles in their decisions. Research, whether clinical (including patients) or laboratorial (involving experimental animals, human tissue and medical records or not) should be conducted ethically, and with the appropriate consents obtained. Privacy and trust of patients, authors and reviewers must be respected. Whenever necessary, rights and permissions need to be required and must be honored. So the key words are: honesty, ethics, respect, trust.

However malicious authors are able to degrade or ignore these principles, with their actions muddying the reputation of research centers, universities and raising questions about possible authorization of the Ethics Committee in Research. The most common scientific errors committed by these kind of irresponsible authors are: appropriation of ideas from other authors, plagiarism, breach of conduct universally accepted in research practice, corruption of legal and regulatory principles, falsification of data, simultaneous submission of papers for two or more journals. In view of the above, authors who incur in faults of such gravity should expect strong attitudes from the entire scientific community to the facts. Editors of scientific journals can not be omitted in face of plagiarism of any kind, duplicate publications of the same work and all other forms of fraud and misconduct mentioned above by authors and their coauthors. These forms of fraud must be held and vigorously repudiated. Co-authors can not claim not to know the frauds, since they have signed a document guaranteeing their effective participation in the work, and therefore know exactly when a work is plagiarism or was submitted simultaneously to more than one journal. All serious journals require a subscription of all authors and coauthors at the time of submission. Their joint signature ensures that the product was subjected to only one publication. Once accepted, authors transfer rights on the material to be published to the entity responsible for publishing. Therefore, it can also be framed as misrepresentation, the simultaneous submission of the same material to two journals. Author and authors should expect the final decision on acceptance or not before considering a new submission.

The Revista Brasileira de Anestesiologia, through its Editor and Editorial Board in respect of its readers and concerned about the reputation hard and gradually achieved, need to alert that it was a victim of such fraud, which resulted in simultaneous publication of that article in the Revista Brasileira de Anestesiologia and Anesthesiology Research and Practice. The article was published simultaneously in the same month in both publications, making it clear that it was submitted in nearby dates (or on the same date) to both journals.

We are left to adopt measures which are the usual and required before these cases, to alert new authors to the principles of ethics, honesty, respect and trust that should be adopted in their research and hope that the Revista Brasileira de Anestesiologia, as well as other journals are not victims of fraud perpetrated by unscrupulous authors. 